\section{USE OF VISUAL AIDS IN TEACHING SKILLED MANIPULATIVE TASKS}

\author{
By Prof. M. D. VERNON
}

\section{Department of Psychology, University of Reading}

$I^{\mathrm{N}}$ NCREASING interest has been aroused in recent years in the possibility of devising improved methods of teaching manipulative tasks of all levels of complexity. Often instructors are not readily available for teaching; or their skill in teaching, as apart from their ability to porform the tasks themselves, may be deficient. The current popularity of 'visual aids' in education-films, film-strips, television, etc.-has suggested that they might be of considerable assistance in the teaching of manipulative tasks. 'They could utilize standardized and efficient methods of instruction; and they could be employed on a large scale, and might obviate the necessity of highly skilled instructors. Indeed, it is claimed that, in the Services, films and film-strips have been found valuable for such instruction.

There has been a tendency to accept uncritically the efficacy of film instruction for teaching manipulative tasks. A recent inquiry by S. Laner ${ }^{1}$, however, suggests that considerable caution is necessary in the use of filmis for this purpose. Laner investigated the effectiveness of film instruction in teaching people to perform three tasks: (1) repairing the sash-cord of $\mathbf{a}$ window; (2) assembling the trigger mechanism of a Bren gun; (3) constructing a complicated paper model. (The films used for tasks (1) and (2) were ordinary commercial films; that used for task (3) was a film specially prepared to give the clearest possible dem.onstration of the method of construction.) The ability of learners to perform these tasks after film instruction was studied individually, and was compared with the ability of other learners to perform the tasks after instruction, in (1) and (3) by film-strip and verbal commentary, in (2) by a written text accompanied by diagrams. The intelligence and 'spatial ability' of the learners varied over a wide range, but was similar on the average for the experimental and control groups.

In general, it was found that the performance of those taught by films was not superior to that of those taught by the other methods. It did not seem that the greater detail, the continuity and the movement of the film had any advantage, even for the understanding of a moving piece of machinery such as the trigger mechanism of the Bren gun. Indeed, the films possessed certain marked disadvantages. They were liable to pass too quickly over the more difficult parts of the task, and the learners had insufficient time for these stages, or wore unable to see them clearly enough. They felt that they were being 'pulled along' by the film displays, and could not control their learning processes. If they failed to grasp clearly the essential stages, their subsequent performance of the task tended to break down.

It transpired that the learners did not acquire passively a train of visual images of the display. Instead, they perceived it actively, and constructed in their minds a kind of plan, described as 'getting the general idea' of the task. This plan was formulated verbally, though accompanied by some visualization, but not by the recall of imagery exactly reproducing what had been shown. The coherence and clarity of the sound commentary were thus of the utmost importance to the formation of the plan. In particular, it could describe the relationships between parts of the material and stages of the task which could not be displayed visually. In the third experiment, one group of learners which was shown the film without any verbal commentary made a much poorer performance than the group which heard the commentary.

On the other hand, the form of the visual display was of comparatively minor importance provided that it could be employed in visualizing effectively some of the steps of the task. Once the 'general idea' had been grasped and the plan formed, the learner could utilize it to perform the task, this performance being more in the nature of an active reconstruction than a mere copying of what was shown in the display. This is not to claim that there is no necessity for employing any form of visual display in the instruction of skilled manipulative tasks. But it need not be a detailed copy of the manipulation; it must rather afford the learner the kind of information which he can employ most readily in formulating his plan of action. For this purpose, diagrammatic material may often be more effective than pictorial material.

This work was carried out in the Department of Psychology at the University of Reading, by means of a grant from the Nuffield Trustees, to whom grateful acknowledgment is made.

1 Ianer, S., Quart. $J$. Exp. Psychol., 6, 95 (1954) ; Bmt. J. Psychol., 44, $280(1955)$; "An Experimental Study of Pictorial Methods
Instruction", unpublished Ph.D. thesis, University of Reading.

\section{THE BRITISH FLORA DURING 1956}

THE progress made in increasing knowledge of the flora of the British Isles during 1956 has been equal to that of recent years ${ }^{1}$. In spite of much inclement weather hampering field work, at least one species of outstanding interest has been added to our list, while important extensions of range have been reported for some of our rarest species. Very satisfying progress has been made in recording general distribution and in the study of variation, while it is evident that some of the new work initiated during the year offers considerable promise for the future. All these aspects were represented at the annual exhibition meeting of the Botanical Society of the British Isles, arranged in the lecture room of the British Museum (Natural History) on November 24. The meeting was attended by about 350 members and guests, and a full account of the exhibits will appear in the Proceedings of the Society.

The most important addition to the British flora is Hypericum canadense L., which has been found by Prof. D. A. Webb in boggy pools and channels by Lough Mask in western Mayo and western Galway. It was exhibited by D. McClintock. This species has a wide range in eastern North America and must be added to the small group of plants which comprise the 'North American element' in our flora, and are all associated with lakes or their vicinity. $H$. canadense has been found growing recently in France under very similar conditions ${ }^{2}$, and while its occurrence there in a limited area as far east as HauteSaône is puzzling, the discovery in Ireland adds support to the suggestion that in France it is a relict species. 